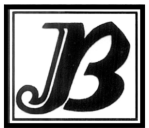

J. Bio-Sci. 29(1): 49-58, 2021 (June)

ISSN 1023-8654 http://www.banglajol.info/index.php/JBS/index DOI: https://doi.org/10.3329/jbs.v29i0.54821

\title{
INVESTIGATION OF LESIONS IN GOAT BRAIN COLLECTED FROM ABATTOIRS IN RAJSHAHI METROPOLITAN AREA
}

\author{
A Akta, R Khatun, MN Khatun, R Parvin, N Khatun, SMA Rauf and HM Golbar* \\ Department of Veterinary and Animal Sciences, University of Rajshahi, Rajshahi-6205, Bangladesh
}

\begin{abstract}
Brain lesions are important cause of morbidity and reduced productivity in goats worldwide. Works on brain lesion in goats are extremely rare in Bangladesh and remain to be investigated. We investigated lesions in goat brains collected from abattoirs in Rajshahi Metropolitan area by gross and microscopic examination. Randomly selected 57 goat brains were investigated of which $24.56 \%$ brains showed gross and histopathologic lesions. Prevalence of brain lesions were higher in Jamnapari goats (29.41\%) compared to in Black Bengal goats (22.50\%) and female goats (26.47\%) were more affected than male goats $(21.74 \%$ ). Age-wise prevalence were $31.25 \%, 21.43 \%, 12.50 \%$, and $40.00 \%$ in the age of up to 2 years, 2-3 years, 3-4 years, and above 4 years old goats, respectively. Goats were more affected in the rainy (35.29\%) season in contrast to in the winter (23.53\%) and in the summer (10.52\%) seasons. The brains collected from goats with Gid disease showed uni or multilocular cysts containing clear fluid and multiple scolices, the rest of the brains were apparently healthy by macroscopic examination. Histopathologically, pyogranuloma, perivascular cuffing, gliosis, neuronal degeneration, hemorrhages, congestion and thrombus were evident.
\end{abstract}

Key words: Abattoir, Brain, Goat, Histopathology, Lesion

\section{Introduction}

Bangladesh is an agro-based country. Livestock plays an important role for the earnings of livelihood of her population, $20 \%$ of the population directly and $50 \%$ of the population indirectly live on livestock business and contributes significantly in the poverty alleviation and supply of rich protein of high caloric value in terms of milk, meat and egg (Chowdhury et al. 2019). Goat is an important member of livestock population providing meat and skin. However, its productivity decreases due to affection with different diseases. Barind tract encompasses geographic region in parts of northwestern Bangladesh including Rajshahi, Chapainawabganj and Naogaon districts and is unique in terms of geo-climatic conditions and goat population. Mainly two goat breeds namely Jamnapari and Black Bengal are reared in Bangladesh. Black Bengal is only native goat breed of Bangladesh but also indigenous to northeastern India, West Bengal, Bihar, and Orissa (Siddiki et al. 2019). The Jamnapari goat, on the other hand, is the best dairy goat in India (Rout et al. 1999). They are the tallest breed and commonly known as the Pari (Angel) in its area of origin - Uttar Pradesh - because of its majestic appearance (Miah et al. 2016). Brain is the most complex organ and serves as the center of the nervous system that control over the other organs in all vertebrate's body. It acts on the rest of the body both by generating patterns of muscle activity and by driving the secretion of chemicals called hormones. This centralized control allows rapid and coordinated responses to changes in the environment. Diseases

*Author for correspondence: golbar@ru.ac.bd 
affecting brains of goats comprise conditions that cause economic losses globally through morbidity and reduced productivity (Konradt et al. 2017).

Brain may be affected by infectious agents such as bacteria, viruses, protozoa, parasites or by deficiency of vitamins and minerals (Windsor et al. 2011). It may be affected by infectious agents through hematogenous or lymphatic dissemination deriving from distant sites, direct penetrating lesions, through an adjacent suppurative lesion or centripetal ascending infection through peripheral nerves and causes neurological disorders and mortality (Fecteau et al. 1997, Morin et al. 2004, Radostits et al. 2007, Kessell et al. 2011, Allen et al. 2013). The areas of the brain most frequently affected are the cerebral cortex, corpus striatum (basal ganglia), and cerebellar peduncles (Orteqa et al. 2019). Coenurus cerebralis, the larval stage of the tapeworm Taenia multiceps is known to affect brain causing Gid disease in goats (Nooruddin et al. 2000, Amin et al. 2013). Toxoplasmosis, a protozoan disease with zoonotic importance also affects brains in goats. Despite tremendous contribution of goats in the economy of Bangladesh, works on brain lesions in goats are extremely rare and remain to be investigated. Therefore, the research was planned to shed some light on the prevalence of brain lesions, the factors affecting prevalence of the brain lesions, and to characterize the lesions histopathologically in goats in the Barind tract.

\section{Materials and Methods}

A total of 57 brain samples collected randomly from goats immediately after slaughter at the abattoirs of Rajshahi metropolitan area during April 2017 to March 2018 were used for this study. The representative tissue samples were immersed in 10\% neutral buffered formalin and shifted to the Department of Veterinary and Animal Sciences, University of Rajshahi and fixed for $24 \mathrm{~h}$. Animal data such as age, sex, breed, and gross changes of brains were collected in a structured data collection form. The tissue samples were processed following standard procedure for histopathologic studies (Golbar et al. 2013). Briefly, the tissues were dehydrated through ascending grades of alcohol, cleared by three changes in xylene and embedded in paraffin. The paraffin embedded tissues were sectioned at $5 \mu \mathrm{m}$ in thickness by using a semi-automatic rotary microtome (MosbiTM, China), stained routinely with Mayer's hematoxylin and Eosin (H\&E) and examined under a light microscope. The images of the tissue sections were grabbed by using a photographic microscope system (Digital camera model: LC-20, Labomed, Inc., USA fitted with a microscope, Model MBL2100, Krüss, Germany).

\section{Results}

This study aimed to characterize lesions of goat brains collected from abattoirs in Rajshahi metropolitan area. The goat brain samples were evaluated based on gross and histopathology and in relation to epidemiological data such as age, sex, breed, and seasons of the year. Out of the 57 goat brains examined $70.18 \%$ of the brains were from Black Bengal goats and 29.82\% from Jamnapari goats. Considering the sex, $40.35 \%$ brain samples was from male goats and $59.65 \%$ from female goats. Overall prevalence of brain lesions was $24.56 \%$ by histopathologic examination. The prevalence of brain lesions associated with age, sex, breed, seasons and histopathologic types have been documented.

\section{Age-wise prevalence of brain lesions in goats}

During the study, the goats examined were divided into 4 groups according to their age as determined by dental chart (Vatta et al. 2007). Group-1 consisted of goats less than two year of age and showed a prevalence of brain lesions of $31.25 \%$ (Fig. 1A). Clinically, some of the goats showed circling movements 
and the brains showed uni or multilocular cysts by gross examination indicating Gid disease as described below. Group-2 included the goats of 2-3 years old and examined the highest number of goats (28 goats) among the age groups, and the prevalence of brain lesion in this age group was $21.43 \%$. Goats with age between 3-4 years belonged to group-3 and showed a brain lesion prevalence of $12.50 \%$. Finally, goats greater than 4 years of age were included in group- 4 and calculated prevalence of brain lesion in the group was $40.00 \%$. Goats of this group were mainly female Jamnapari. The affection of brain lesions within the total population were $8.77,10.53,1.75$ and $3.51 \%$ in goats of $<2$ years, $2-3$ years, $3-4$ years and $>4$ years old, respectively.

\section{Sex-wise prevalence of brain lesions in goats}

Sex was found an important determinant on the prevalence of brain lesions in goats. In this investigation, $26.47 \%$ female goats and $21.74 \%$ male goats were affected with brain lesions (Fig. 1B). It was important to note that the female goats were more affected with brain lesions than the male goats. Additionally, among the female goats affected with brain lesions, $14.71 \%$ was Black Bengal and $11.76 \%$ was Jamnapari. On the other hand, among the male goats, $17.39 \%$ was Black Bengal and $4.35 \%$ was Jamnapari. Finally, $15.79 \%$ of the brain lesions came from female goats and $8.77 \%$ from male goats (Table 1 ).
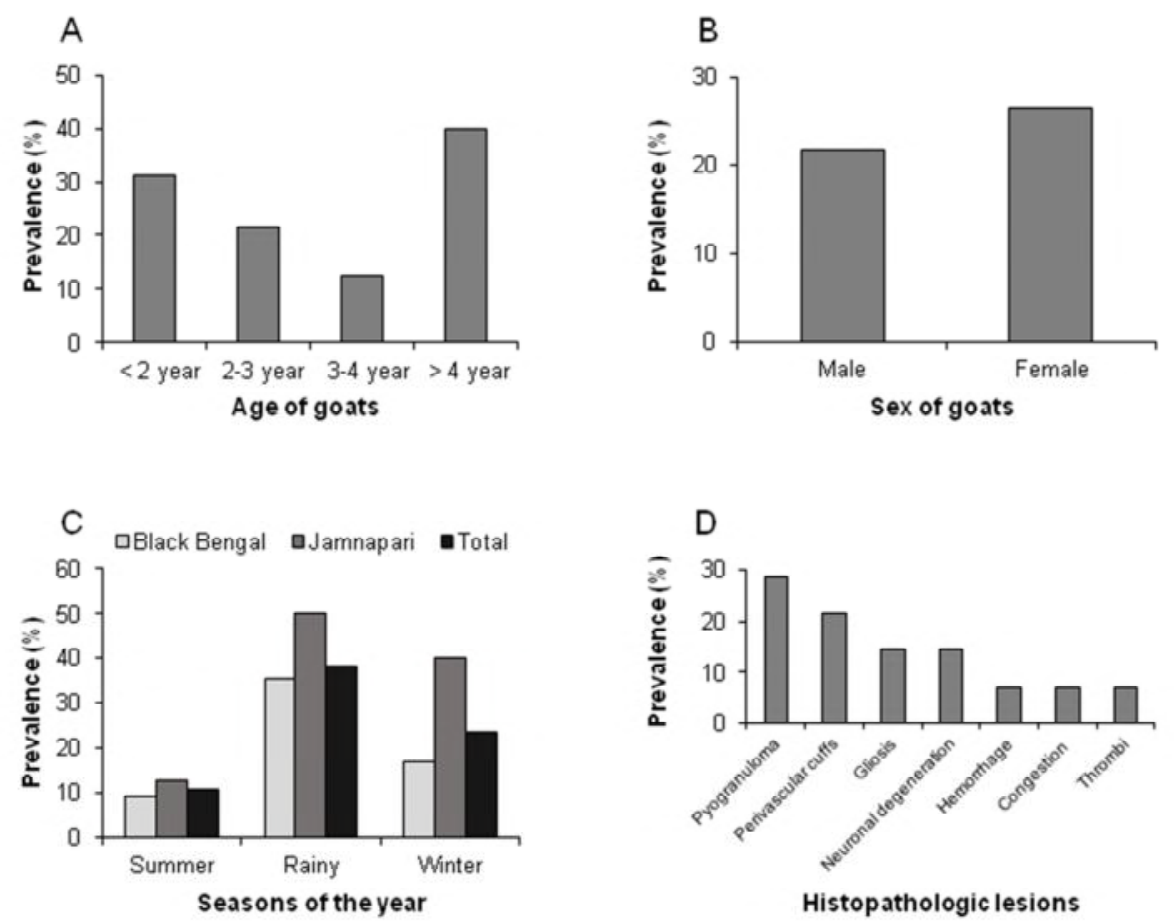

Fig. 1: Prevalence of brain lesions based on age, sex, season and histopathologic types in goats. Brain lesions were highest in more than 4 years of age followed by less than 2 years, 2-3 years and lowest in 3-4 years age (A). Brain lesions were higher among female goats than male goats (B). 
Prevalence of brain lesions was the highest in the rainy season than in the winter and in the summer seasons. Jamnapari goats were more affected than Black Bengal goats in all seasons (C). Histopathologic types of lesions showing highest prevalence of pyogranuloma followed by perivascular cuffs, gliosis and neuronal degeneration were recorded in this study (D). Hemorrhage, congestion and thrombus were the lowest and did not vary each other.

\section{Breed-wise prevalence of brain lesions in goats}

During the examination of brain lesions in goats slaughtered in the abattoirs of Rajshahi Metropolitan area, two goat breeds, categorized based on dominant breed characteristics, prevailing in the area were encountered and they were Black Bengal and Jamnapari. Brain lesions among the goats examined were $15.79 \%$ from Black Bengal and $8.77 \%$ from Jamnapari. Among the breeds, $22.50 \%$ of the Black Bengal goats and $29.41 \%$ of the Jamnapari goats were affected with brain lesions (Table 1).

Table 1. Sex-wise prevalence of brain lesions in goats

\begin{tabular}{clccc}
\hline Sex & Breed & $\begin{array}{c}\text { Number of } \\
\text { brain examined }\end{array}$ & $\begin{array}{c}\text { Number of brain } \\
\text { affected }\end{array}$ & Prevalence (\%) \\
\hline \multirow{2}{*}{ Female } & Black Bengal & 23 & 5 & 26.47 \\
& Jamnapari & 11 & 4 & \\
\multirow{2}{*}{ Male } & Black Bengal & 17 & 4 & 21.74 \\
& Jamnapari & 6 & 1 & 24.56 \\
& Total & 57 & 14 & \\
\hline
\end{tabular}

\section{Season-wise prevalence of brain lesions in goats}

The prevalence of brain affections was different in different seasons. Among the brain lesions of the goats examined, overall, the highest prevalence was recorded in the rainy season which is $38.09 \%$ followed by in the winter (23.53\%) and in the summer (10.53\%) seasons (Fig. 1C). Within the breeds, $35.29 \%$ of the Black Bengal and $50.00 \%$ of the Jamnapari goats were affected with brain lesions during the rainy season. On the other hand, in the winter season, $16.67 \%$ of the Black Bengal and $40.00 \%$ of the Jamnapari goats were affected. In the summer season, affection of brain lesions in Black Bengal goats was $9.09 \%$ and in Jamnapari goats was $12.50 \%$. It was worthy to note from the study that the prevalence was higher in Jamnapari goats (50.00, 40.00 and 12.50\%) than in Black Bengal goats (35.29, 16.67 and 9.09\%) in the rainy, winter and summer seasons, respectively. Overall, the brain lesion due to seasons was $14.04 \%$ in the rainy season, $7.02 \%$ in the winter season and $3.51 \%$ in the summer season.

\section{Prevalence of brain lesions based on histopathologic types in goats}

The brains which were macroscopically normal (Fig. 2A) supported by absence of any abnormality in histologic sections (Fig. 3A) served as control. Most brains examined were apparently normal by macroscopic examination except cystic structures, uni or multilocular, in some brains and were diagnosed as Gid diseases (Fig. 2B). Histopathologically, seven different types of lesions such as pyogranuloma (7.01\%), 
perivascular cuffs $(5.26 \%)$, gliosis (3.51\%), neuronal degeneration (3.51\%), hemorrhage $(1.75 \%)$, congestion of vessels $(1.75 \%)$ and thrombus (1.75\%) were documented. Out of the histopathologic lesions, pyogranuloma was the highest (28.57\%) and was characterized by neuronal degeneration and multifocal infiltration of inflammatory cells mainly involving lymphocytes (Fig. 1D, Fig. 3B). Perivascular cuffs were found in $21.43 \%$ of affected goat brains and were characterized by aggregation of mononuclear leukocytes around the blood vessels. Perivascular cuffs, in most cases, were associated with glial cell proliferation (Fig. 3C). Gliosis ranked third most prevalent lesions and an equivalent to neuronal degeneration (14.29\%) and was caused by the proliferation of astrocytes, microglia and oligodendrocytes. Neuronal degeneration, on the other hand, was identified by the presence of empty spaces around the neuron (Fig. 3D). Hemorrhage and congestion were found in $7.14 \%$ cases each of the goat brains examined. Interestingly, antemortem intravascular blood clotting called thrombus was found in one goat (7.14\%). The thrombus was characterized by its attachments with the vessel wall and absence of regular lamination (Fig. $3 \mathrm{E}$ ). There was proliferation of meningeal cells along with infiltration of inflammatory cells mainly involving lymphocytes in the submeningeal tissues in the brain affected with Coenurus cerebralis (Gid disease) (Fig. 3F). The neuronal tissues beneath the meninges were compressed and atrophied.
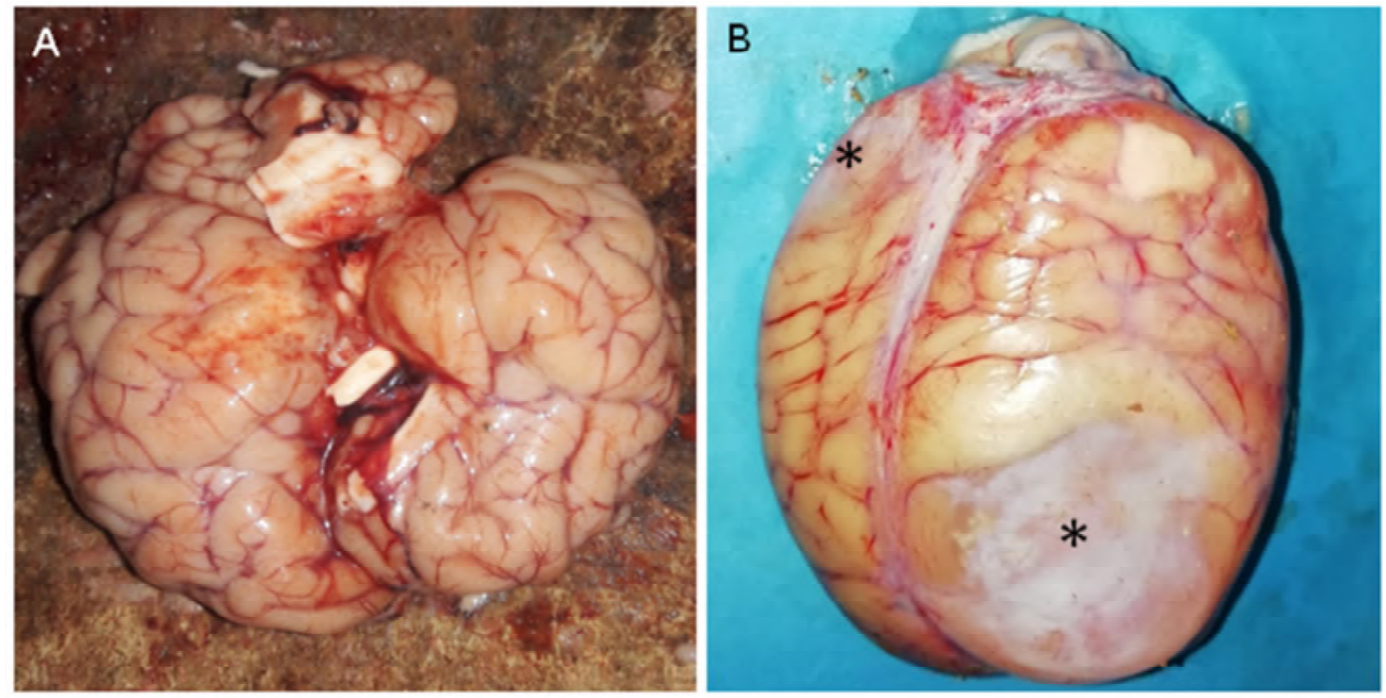

Fig. 2(A-B): Gross images of goat brains. Control brain showing no abnormality (A). Brain with multilocular cysts of Coenurus cerebralis (asterisks) in the left frontal and right occipital lobes (B). 

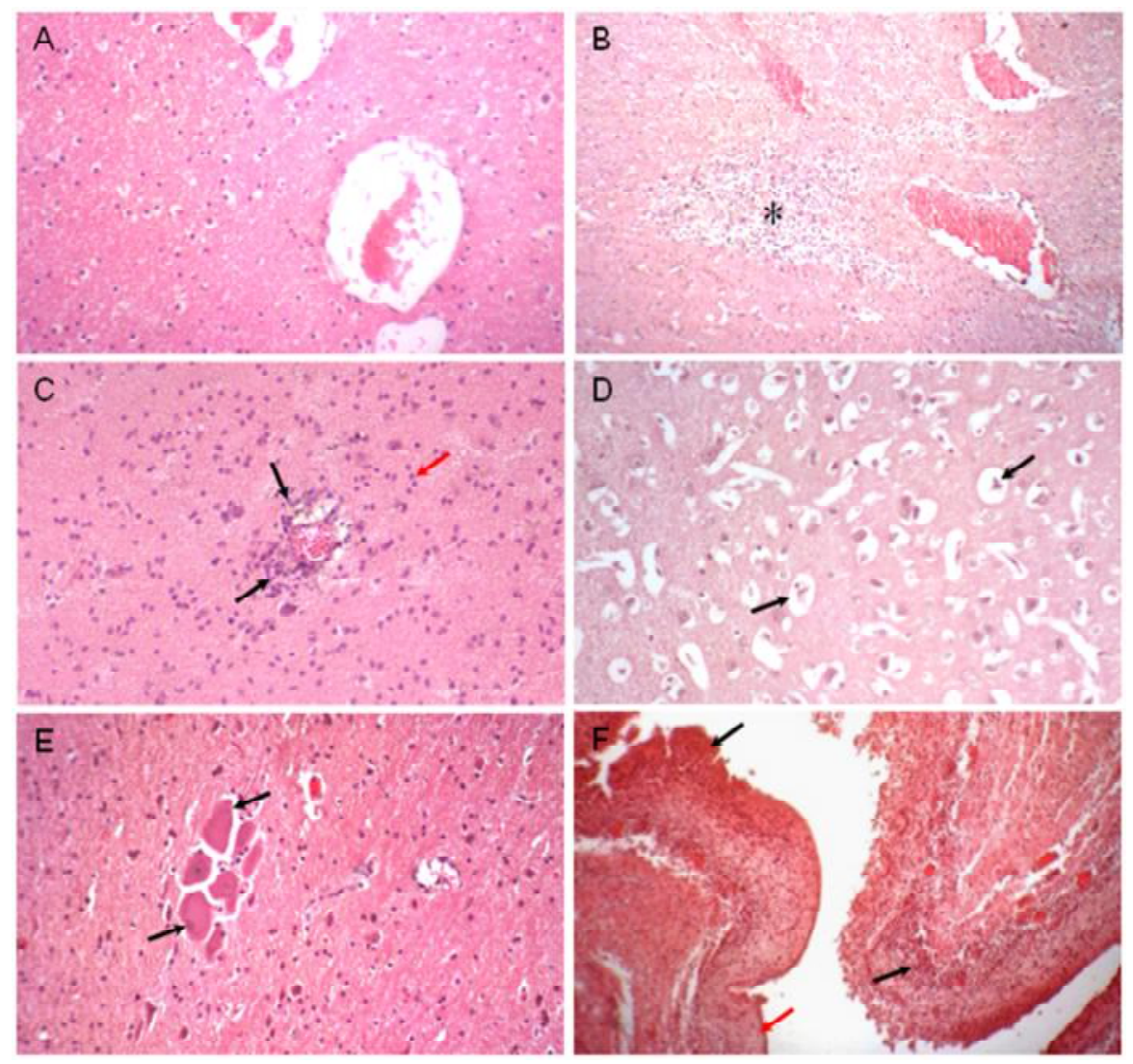

Fig. 3(A-F): Microscopic images of goat brain sections. Section of control brain (cerebrum) from a healthy goat showing normal architecture (A), Non-supportive encephalitis showing focal infiltration of mononuclear cells (asterisk) with neuronal degeneration (B), Perivascular cuffing (black arrow) and severe gliosis (red arrows) (C), Neuronal degeneration with loss of cytoplasm (arrows) in cerebrum (D), Section showing thrombi attached to the wall within a blood vessel $(E)$, Inflammation, proliferation of meningeal cells (black arrow) and compression of nerve tissues in cerebrum from Gid disease (red arrow), and Hematoxylin and eosin stain (F).

\section{Discussion}

Goats make important contributions to earning human livelihoods in developing economies, since they are extremely hardy animals that can survive and reproduce under extremely high temperatures and low humidity with minimum available feed. A study was conducted on brains of goats to determine the different brain lesions for a period of one year in Rajshahi metropolitan area. Fourteen goat brains out of the 57 brains examined were with different brain lesions with the prevalence of $24.56 \%$.

\section{Age-wise prevalence of brain lesions in goats}

The current research revealed that goats of $<2$ years age group are mostly affected with brain lesions $(31.25 \%)$. Underdeveloped immune system, microbial infection associated with sudden change of weather, 
or parasitic infection especially with Coenurus cerebralis may predispose the higher prevalence of the brain lesion in this age group (Hashim et al. 2000). According to Gicik et al. (2007) selling of sick animals to abattoirs or market by owners as soon as they notice the coenurosis without informing the local authorities leads to the high prevalence of Coenurus cerebralis in the area. Although the highest prevalence (40\%) of brain lesions was found in goats of $>4$ age, this prevalence may not represent the real status as a few animals (only 5 goats) were examined in this group. Besides, poor body conditions, sudden feeding changes, consumption of poor quality or spoiled feedstuffs in combination with environmental stress factors (weaning), stress of kidding, poor flock management (husbandry, nutrition, preventive medicine and others), decreased immune function with the advancement of age during the winter and rainy months consuming poor quality silage may be some factors for the highest prevalence of brain lesions in this age group (Zoe et al. 2016). The prevalence rates in 2-3 years and $3-4$ years were $25.00 \%$ and $12.50 \%$, respectively. In this study, goats of 3-4 years age group showed reduced incidence rate compared to $<2$ years and 2-3 years age groups. Young goats may also have decreased immunity due to underdeveloped immune system and the prevalence rates may reduce with the increase of age because of development of immunity (Matos el al. 2015, Biobaku and Amid 2018).

\section{Sex-wise prevalence of brain disease of goats}

Different sex revealed different prevalence of brain lesions. This experiment revealed that male goats were affected less (21.74\%) than those of female goats (26.47\%). Normally, female goats are more susceptible to infection than male goats due to stress to kidding, milk yield and rearing for longer period for breeding purposes (Hossain et al. 2011, Islam et al. 2016). This study revealed that the infected goats were mostly older females. Blood et al. (2006) documented that female goats which are usually weak and malnourished, generally are more susceptible to infections.

\section{Breed-wise prevalence of brain lesion in goats}

Breed is one of the most important risk factor of diseases in goats. This experiment showed that Black Bengal goats are less susceptible to brain affections than Jamnapari goats. Reports from several other authors also recorded higher susceptibility of diseases in exotic animals than in native animals (Wambura et al. 1998, Brotherstone et al. 2010). Although Black Bengal goats are widely distributed throughout the country, the Jamnapari goats are available in the Rajshahi areas and the goats come to the slaughter houses from markets of upazillas of Rajshahi and Chapainawabganj districts representing Barind tract area. Though these two types of breeds are highly prolific but most of the Jamnapari goats are reared for milk and the Black Bengal goats for meat and skin. The Jamnapari becomes older for their milking and breeding purpose usages and becomes infected with brain lesions.

\section{Season wise prevalence of brain lesion in goat}

Season is one of the factors that influence the prevalence of brain lesions. This experiment showed that prevalence rate in the rainy season is higher (35.29\%) than the prevalence rate in the winter season (25.00\%). The infection is linked with open grazing after heavy rainfall (Hossain et al. 2011). Sudden change in the weather is responsible for growth of bacteria which increase the prevalence rate of disease (Hossain et al. 2011). The higher percentages of ecological variables (rainfall, relative humidity and air temperature) are considered to be influencing factors for coenurosis and in the rainy season, rain causes spread of feces of dog, fox (final host) over the grasses and these contaminants are responsible for the increased occurrence of Gid disease during rainy season (Hashim et al. 2000, Nourani and Kheirabadi 2009). This study documented pyogranuloma in $28.57 \%$ cases in the rainy and winter seasons. According to Allen et al. (2013), the 
experiment undertaken by them found $50 \%$ cases of Listeriosis out of 139 goats and they recorded most cases $(60 \%)$ in the fall and winter.

\section{Lesion wise prevalence of brain lesions in goat}

The current study revealed four goats (28.57\%) affection with focal inflammatory infiltration of mononuclear cells (pyogranuloma) in cerebrum. Pyogranuloma associated with mononuclear cell infiltration is generally found in Listeriosis (Allen et al. 2013, Headley et al. 2013) and Toxoplasmosis (Moreno et al. 2012). In the investigation, three goats (21.43\%) were diagnosed with perivascular cuffing and severe gliosis in cerebrums. Perivascular cuffing is found in Toxoplasma gondii infection (Matos et al. 2015, Nunes et al. 2015). Perivascular cuffing and gliosis in cerebrum have been documented in association with Toxoplasma gondii infection in goats (Moreno et al. 2012, Wanderley et al. 2015). Perivascular cuffing is also found in the Listeriosis in goats (Allen et al. 2013). Therefore, the pyogranuloma and perivascular cuffs found in the current study may be due either to Listeriosis or Toxoplasmosis or the both. Two goats (14.29\%) were found to have neuronal degeneration in cerebrum of the brain. The cytoplasm of the neuron was almost lost and only the nuclei were evident in most neurons of the neuronal degeneration. Neuronal degeneration, known as polioencephalomalacia (PEM), occurs in goats in association with a functional thiamine (vitamin B 1) deficiency, sulfur toxicosis, water deprivation-salt toxicity, lead poisoning, hypoxia or by copper deficiency (Allen et al. 2013). In the present study, cause for the lesion was not determined. One goat (7.14\%) in the present study was diagnosed with hemorrhage and congestion in cerebrum. Hemorrhage could be found in the Toxoplasma gondii infection in goats (Wanderley et al. 2015). However, how the vascular congestion develops in the brain of the encephalitic Listeriosis in small ruminants require further clarification. The current study revealed thrombus in the cerebral cortex in one (7.14\%) goat. Because the brain samples were collected from slaughtered goats at the abattoirs, therefore, it is important to distinguish the thrombus from postmortem clot. The postmortem clot becomes laminated and takes the shape of blood vessel in which the clot is formed (Jones et al. 1997). In the current study, the clot was not laminated and did not take the shape of blood vessel, rather it was attached to the blood vessel, an indication of antemortem thrombus (Jones et al. 1997). However, due to lack of data, it is difficult to interpret on the cause of thrombosis of the goat and needs further study.

One serological study by ELISA revealed 31-55\% prevalence of Toxoplasmosis in goats in Rajshahi region (Rahman et al. 2015). Based on the findings of the serological investigation an important target of the current study was to find the Toxoplasma cysts in the brain tissues by histopathology. Unfortunately, this study did not find any Toxoplasma cyst in the brains examined to correlate with the antibody dependent seropositivity of Toxoplasmosis although pyogranuloma and perivascular cuffs, which are commonly found in association with Toxoplasma infection, were evident. One explanation of not finding Toxoplasma cyst in the current study may be that only little amount of brain tissue, a few sections of $5 \mu \mathrm{m}$ thick per brain, were examined in the histopathologic investigation. Another explanation may be that the Toxoplasma antibody developed during active infection and persisted even after recovery. However, to come in final conclusion on the presence or absence of Toxoplasma cyst in the goat brain, whole brain should be scanned by crushing and examining under microscope, which is tedious and time consuming and practically impossible based on volume of the goat brain.

\section{Acknowledgments}

This work was supported in part by grant from University of Rajshahi No: A-268/5/52/RU/Agri-18/201718/218 (to HM Golbar and SMA Rauf). 


\section{References}

Allen AL, Goupil BA and Valentine BA (2013). A retrospective study of brain lesions in goats submitted to three veterinary diagnostic laboratories. Journal of Veterinary Diagnostic Investigation, 25: 482-489.

Amin MN, Hashim MA, Hossain MA and Al-Sultan II (2013). Coenurus cerebralis infection (Gid disease) in Black Bengal goats; Effects on certain blood values after surgical treatment. Journal of Advanced Biomedical \& Pathobiology Research, 3: 1-7.

Biobaku KT and Amid SA (2018). Predisposing factors associated with diseases in animals in Nigeria and possible botanical immunostimulants and immunomodulators, Bangladesh. Journal of Veterinary Medicine, 16: 87-101.

Blood DC, Radostits OM, Gay CC, Hinchcliff KW and Constable PD (2006). Veterinary Medicine: a text book of the diseases if cattle, sheep, goats, pig and horses. 10 th Edition. Elsevier, London, New York, Oxford, pp. 1378-1382.

Brotherstone S, White IMS, Coffey M, Downs SH, Mitchel AP, Clifton-Hadley, More SJ, Good M and Woolliams JA (2010). Evidence of genetic resistance of cattle to infection with Mycobacterium bovis. Journal of Dairy Science, 93: 1234-1242.

Chowdhury SMZH, Mahmud MS, Islam MR and Nazir KHMNH (2019). Phylogenetic analysis of black Bengal and Jamunapari goats in Bangladesh based on partial sequence of cytochrome b gene. SAARC Journal of Agriculture, 17: 23-35.

Fecteau G and George LW (2004). Bacterial meningitis and encephalitis in ruminants. Journal of the Veterinary Clinics of North America: Food Animal Practice, 20: 363-377.

Fecteau G, Van Metre DC, Pare J, Smith BP, Higgins R, Holmberg CA Jang S and Guterbock W (1997). Bacteriological culture of blood from critically ill neonatal calves. The Canadian Veterinary Journal, 38: 95-100.

Gicik Y, Kara M and Arsalan MO (2007). Prevalence of coenurus cerebralisin sheep in kars province, Turkey. Journal of Bulletin Veterinary Institute, Pulawy, 51: 379-382.

Golbar HM, Izawa T, Juniantito V, Ichikawac C, Tanaka M, Kuwamura M and Yamate J (2013). Immunohistochemical characterization of macrophages and myofibroblasts in fibrotic liver lesions due to fasciola infection in cattle. The Journal of Veterinary Medical Science, 75: 857-865.

Hashim MA, Rashid MH and Nooruddin M (2000). Extraneural coenuriasis in Bengal goats.4.Treatment. Journal of the Bangladesh Veterinarian, 17: 46-49.

Headley SA, Bodnar L, Fritzen J TT, Bronkhorst DE, Alfieri AF, Okano W and Alfieri AA (2013). Histopathological and molecular characterization of encephalitic Listeriosis in small ruminants from northern Paraná, Brazil. Brazilian Journal of Microbiology, 44: 889-896.

Hossain MM, Paul S, Rahman MM, Hossain FMA, Hossain MT and Islam MR (2011). Prevalence and economic significance of caprine fascioliasis at Sylhet district of Bangladesh. Pakistan Veterinary Journal, 31: 113-116.

Islam KM, Islam MS, Rauf SMA, Khan A, Hossain KMM and Rahman M (2016). Patho-surveillance and pathology of fascioliosis (Fasciola gigantica) in Black Bengal goats. The Journal of Advances in Parasitology, 3: 49-55.

Jones TC, Hunt RD and King NW (1997). Veterinary Pathology. th $^{\text {th }}$ edition. Williams and Wilkins, Philadelphia, USA, pp. 1392.

Kessell AE, Finnieb JW and Windsorc PA (2011). Neurological diseases of ruminant livestock in Australia. III: bacterial and protozoal infections. Australian Veterinary Journal, 89: 289-296.

Konradt G, Bassuino DM, Prates KS, Bianchi MV, Snel GGM, Sonne L, Driemeier D and Pavarini SP (2017). Suppurative infectious diseases of the central nervous system in domestic ruminants. Pesquisa Veterinária Brasileira, 37: 8

Matos L, Muñoz MC, Molina JM, Rodríguez F, Pérez D, López AM, Hermosilla C, Taubert A and Ruiz A (2015). Agerelated immune response to experimental infection with Eimeria ninakohlyakimovae in goat kids. Research in Veterinary Science, 118:155-163. 
Miah G, Das A, Bilkis T, Momin MM, Uddin MA, Alim MA, Mahmud MS and Miazi OF (2016). Comparative Study on Productive and Reproductive Traits of Black Bengal and Jamnapari Goats under Semi-Intensive Condition. Scientific Research Journal, 4: 1-7.

Moreno B, Collantes-Fernandez E, Villa A, Navarro A, Regidor-Cerrillo J and Ortega-Mora LM (2015). Occurrence of Neospora caninum and Toxoplasma gondii infections in ovine and caprine abortions. Journal of Parasitology International, 64: 389-391.

Morin DE (2004). Brainstem and cranial nerve abnormalities: Listeriosis, otitis media and pituitary abscess syndrome. Journal of Veterinary Clinics North America: Food Animal Practice, 20: 243-273.

Nooruddin M, Rashid MH and Hashim MA (2000). Extraneural coenuriasis in Bengal goats: Epidemiology Journal of Progressive Agriculture, 11:141-145.

Nourani $\mathrm{H}$ and Kheirabadi KP (2009). Cerebral coenurosis in goats: Pathological findings and literature review. Comparative Clinical Pathology, 18: 85-87.

Nunes ACBT, da Silva EMV, de Oliveira JA, Yamasaki EM, de Cássia Peixoto Kim PCP, de Almeida JC, Nunes KB and Mota RA (2015). Application of different techniques to detect Toxoplasma gondii in slaughtered sheep for human consumption, Brazil. Journal of Veterinary Parasitology, Jaboticabals, 24: 416-421.

Orteqa J, Verdes JM, Morrell EL, Finnie JW, Manavis J and Uzal FA (2019). Intramural vascular edema in the brain of goats with Clostridium perfringens type D enterotoxemia. Journal of Veterinary Pathology, 56: 452-459.

Radostits OM, Gay CC, Hinchcliff KW and Constable PD (2007). Veterinary Medicine: a textbook of the diseases of cattle, horses, sheep, pigs and goats. 10 $10^{\text {th }}$ ed. W.B. Saunders, Edinburg, pp. 2156.

Rahman M, Alauddin M, Hossain KM M, Islam MH, Kitoh K, Nagamune K and Takashima Y (2015). Prevalence and dynamics of antibodies against Toxoplasma gondii in kids born from naturally infected goats. Journal of Parasitology International, 64: 389-391.

Rout PK, Mandal A, Roy R and Singh LB (1999). Improvement and conservation of Jamunapari goats in their home tract. India, Ministry of Agriculture Report, New Delhi, India.

Siddiki AMAM, Billah M, Alam M, Shawrob KSM, Kumkum M, Saha S, Chowdhury M, Rahman AH, Stear M, Khan MKI, Miah G, Mollah AKM and Baten A (2019). Complete mitochondrial genome sequence of Black Bengal goat (Capra hircus). Mitochondrial DNA Part B, 4: 2121-2122.

Vatta AF, Abbot MA, Villiers JF, Gumede SA, Harrison LJS, Krecek RC, Letty BA, Mapeyi N and Pearson RA (2007). Goat keepers' animal health care manual. $2^{\text {nd }}$ Edition. Agricultural Research Council. Onderstepoort Veterinary Institute with KwaZulu-Natal Department of Agriculture and Environment, Onderstepoort 0110, Republic of South Africa, 60.

Wambura PN, Gwakisa PS, Silayo RS and Rugaimukamu EA (1998). Breed-associated resistance to tick infestation in Bos indicus and their crosses with Bos Taurus. Journal of Veterinary Parasitology, 77: 63-70.

Wanderley FS, Porto WJN, Camara DR, de Oliveira VVG, Garcia JL, de Albuquerque PPF, da Fonseca Oliveira AA and Mota RA (2015). Veneral transmission of Toxoplasma gondii in goats after a buck was experimentally infected. Journal of Small Ruminant Research, 123: 301-305.

Windsor PA, Kessell AE and Finnie JW (2011). Review of neurological diseases of ruminant livestock in Australia. Vl: postnatal bovine, and ovine and caprine, neurogenetic disorders. Australian Veterinary Journal, 89: 432-438.

Zoe PS, Nektarios GD, Andreas P and Nikolaos P (2016). Neurological diseases of small ruminants in Greece: A retrospective study in 114 flocks. Journal of Acta Veterinaria-Beograd, 66: 160-171. 